\title{
Bending Fatigue Behavior of Blast Cleaned Grey Cast Iron
}

\author{
Maqsood Ahmad ${ }^{1, a^{*}}$, Ru Lin Peng ${ }^{2, b}$, Mathias König ${ }^{3, c}$, Sten Johansson ${ }^{2, d}$ \\ ${ }^{1}$ Base Engine \& Materials Technology, Volvo Group, SE-40508, Gothenburg, Sweden \\ ${ }^{2}$ Dept of Management and Engineering, Linköping University, SE-581 83 Linköping, Sweden \\ ${ }^{3}$ Materials Technology for Basic engine, Scania CV, SE-15187, Södertälje, Sweden \\ amaqsood.ahmad@volvo.com, bru.peng@liu.se, ${ }^{\mathrm{c}}$ mathias.konig@scania.com, \\ 'sten.johansson@liu.se
}

\section{Keywords: Cast Iron, Blast Cleaning, Machining, Bending Fatigue, Residual Stress}

\begin{abstract}
This paper presents a detailed study on the effect of an industrial blast cleaning process on the fatigue behavior of a grey cast iron with regard to the residual stresses and microstructural changes induced by the process. A comparison was also made to the effect of a machining operation which removed the casting skin layer. The blast cleaning process was found to greatly improve the fatigue resistance in both the low and high cycle regimes with a $75 \%$ increase in the fatigue limit. Xray diffraction measurements and scanning electron microscopic analyses showed that the improvement was mainly attributed to compressive residual stresses in a surface layer up to $800 \mu \mathrm{m}$ in thickness in the blast cleaned specimens. The machining also gave better fatigue performance with a $30 \%$ increase in the fatigue limit, which was ascribed to the removal of the weaker casting skin layer.
\end{abstract}

\section{Introduction}

Blast cleaning is a standard industrial process used in foundries to remove mould residues and oxide scales from the surface of castings. During the process, accelerated hard particles/shots impinge on the cast surface. The impact not only gives the desired cleaning effect but also induces surface plastic deformation and residual stresses, see for example [1], in the same way as the widely used shot peening process for surface strengthening of metallic components. However, being a cleaning process, a high blasting force is often used and little attention is paid to the control of process parameters such as blasting intensity and coverage.

The fatigue behaviour of structural components is sensitive to their surface condition. A blast cleaning process that significantly alters the surface integrity is important for the performance of cast irons subjected to cyclic loading. However, published research work on fatigue of cast irons with casting skin after clean blasting or shot peening are very limited, see however [2-4]. Benefits of blasting [2] or gentle shot peening [3] to the bending fatigue resistance of as-cast compacted graphite irons were reported. In [4] a gentle shot peening was also found to increase the bending fatigue limit of an as-cast grey iron. More publications on machined cast irons can be found, which show that the effect of shot peening varies with the peening parameters and materials. In general, the bending fatigue resistance of machined cast irons can be improved to certain degrees by shot peening, see for example [5] on grey cast iron, [3] on compacted graphite iron, [5,6]on ductile iron and [7] on austempered cast iron. On the other hand, shot peening using high peening intensity may not be beneficial; it was observed in [8] to lower the axial fatigue strength of a machined grey cast iron and in [6] to have no effect on the bending fatigue life of a machined ductile iron. The current work investigated the effect of an industrial clean blasting process on the bending fatigue behaviour of an as-cast grey cast iron. Comparison with machining that removed the casting skin was also made. Four point bending fatigue testing was performed and the results were analysed with regard to 
residual stresses measured by X-Ray diffraction and microstructural changes studied using a scanning electron microscope.

\section{Experimental Details}

The material used in the study is a grey iron grade VIG290/205 equivalent to Mo-Cr-Cu alloyed SSEN-1561-GJL 300. Smooth specimens (Fig. 1) for bending fatigue test were manufactured from cast plates in three different conditions: as-cast, machined and as-blast cleaned. For the as-cast condition, the casting surfaces were gently cleaned using a steel brush. For the blast cleaned condition, a typical process used for in-house cleaning components of heavy duty diesel engines was employed. Steel shots of S390 were used and the blast intensity measured on Almen strips placed in the centre location of the cast plates was averaged to $0.18 \mathrm{mmC}$. For the machined condition, the casting skin was removed by milling, leaving a surface with $\mathrm{Ra} 3.2 \mu \mathrm{m}$ in roughness.

Four-point bending fatigue testing was performed in a MTS hydraulic load frame with a stress ratio of 0.1 and frequency of $25 \mathrm{~Hz}$. Residual stresses were determined on the Ferrite- 211 planes using the standard $\sin ^{2} \psi$ method with $\mathrm{Cr}-\mathrm{K}_{\alpha}$ radiation and $9 \psi$-angles ranging from $-55^{\circ}$ to $+55^{\circ}$. The $\mathrm{X}$-ray elastic constant for stress calculation is $5.81 \cdot 10^{-6} \mathrm{MPa}^{-1}$. Layer removal by electrolytic polishing was combined for measuring residual stresses below the surface. Microstructural analyses on longitudinal cross-sections were carried out in a Field Emission Scanning Electron Microscope.

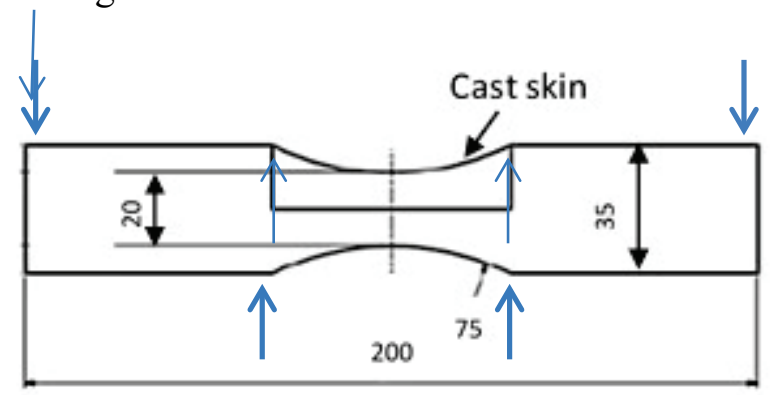

Fig. 1 Geometry of the fatigue specimens with casting skin. Specimen thickness was $15 \mathrm{~mm}$. The gauge section of the machined specimens was reduced to $15 \mathrm{~mm}$ (width) by $10 \mathrm{~mm}$ (thickness) but the radius was kept unchanged. The arrows indicate positions for applying the bending load.

\section{Results and Discussion}

SEM and XRD analyses. As indicated in Fig. 2a, a casting skin, typically $300 \mu \mathrm{m}$ thick, was observed in as-cast specimens. The casting skin contained an outer scale of iron and silicon oxides and a subsurface layer of pearlite with flaky inclusions. EDS analysis revealed that the flaky inclusions were essentially lamellar graphite with Si oxides in the edges. Polygonal grains of mainly ferritic phase were also observed in the casting skin layer (Fig. 2b). The microstructure below the casting skin, as shown in Fig. 2a, consisted of a matrix of essential pearlite and type A graphite.
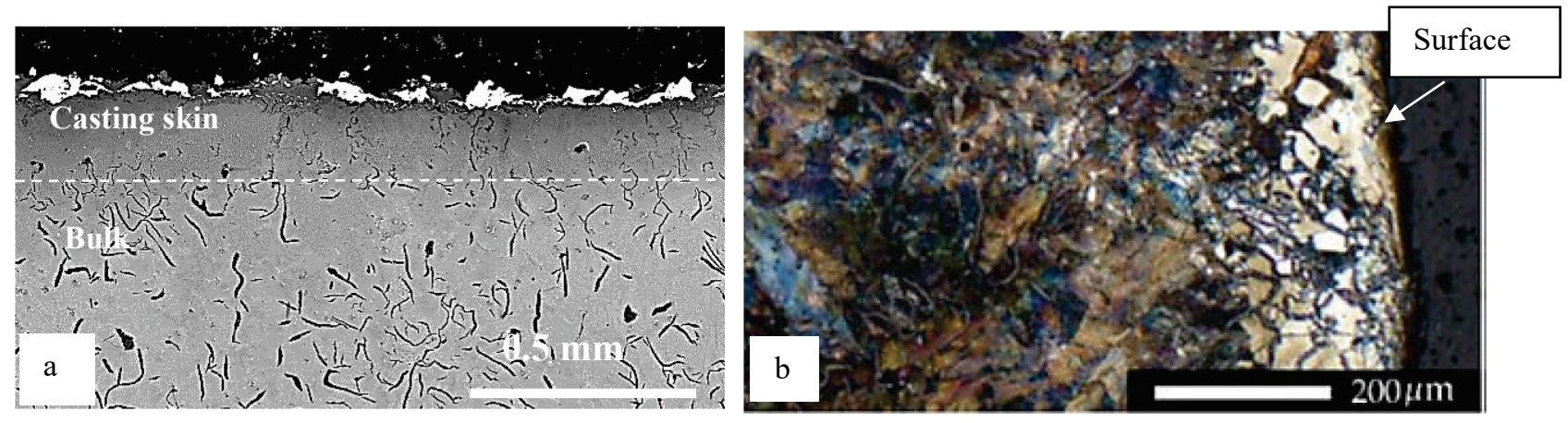

Figure 2. Longitudinal cross-section showing (a) the casting skin with oxide scale (SEM image) and (b) ferrite grains (light grains) in the casting skin (optical micrograph).

Impact of the blasting shots removed the outer oxide scale (Fig. 3a) and also induced heavy plastic deformation in a surface layer (Fig.3b and c). Protrusions formed at the surface in association with reorientation of flaky inclusions (Fig. 3b). However, a comparison of Fig. 3a with Fig. 2a indicated 
similar surface roughness for the as-cast surface and blast cleaned surface. Closer examination of the surface layer under high magnifications dislocated the formation of massive micro cracks in embedded oxides, which did not seem to propagate into the surrounding matrix, as shown in Fig. 3c. This is in contrast to one of our previous studies where microcracks were common in machined specimens of the same material after shot peening using $0.16 \mathrm{mmC}$ intensity [8]. That the casting skin layer better withstood the impact load could be attributed to a damping effect of the oxide scale and better ductility of the casting skin layer containing polygonal ferrite-grains.
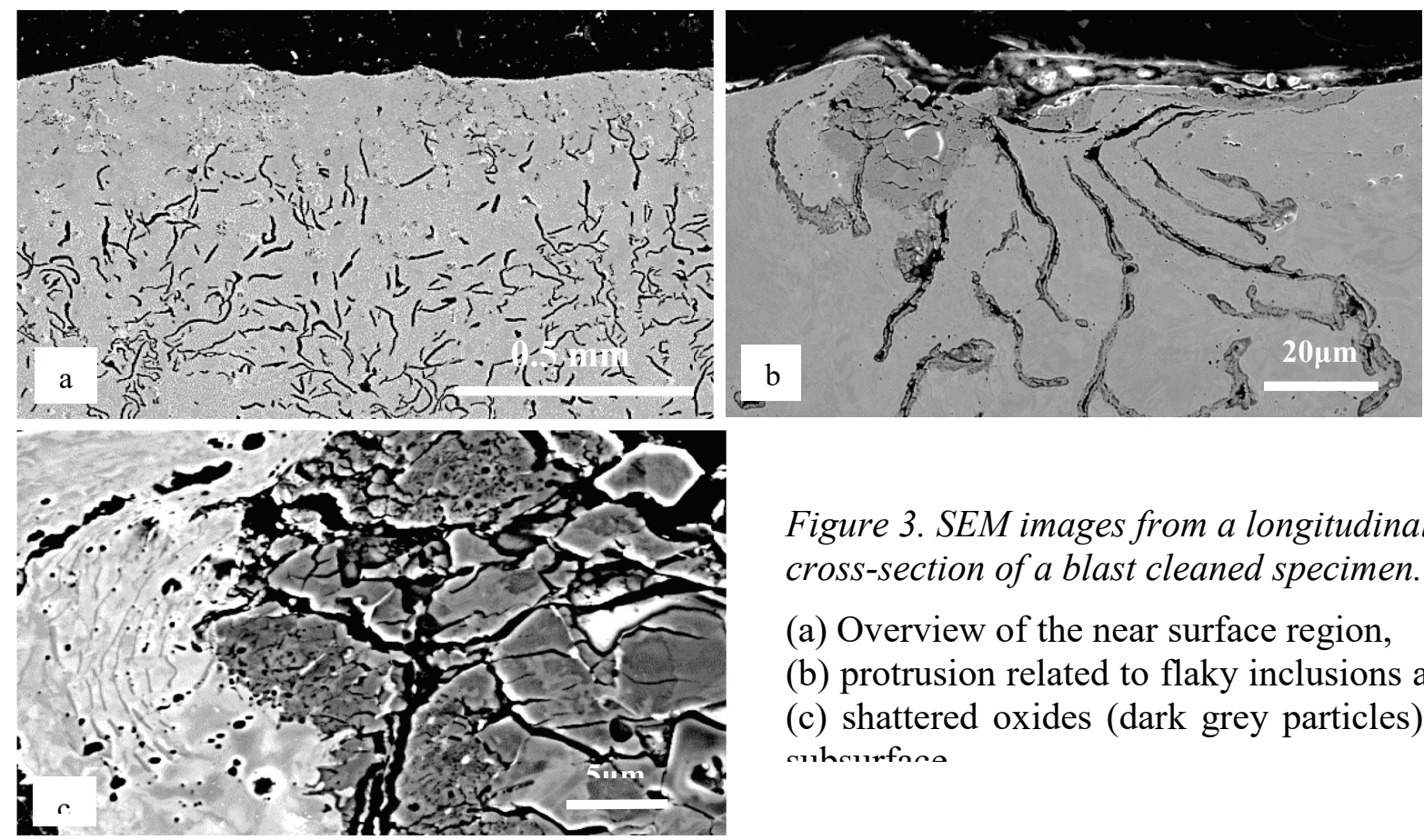

Figure 3. SEM images from a longitudinal cross-section of a blast cleaned specimen.

(a) Overview of the near surface region,

(b) protrusion related to flaky inclusions and

(c) shattered oxides (dark grey particles) in mihourfono

Hardness measured in the matrix of the casting skin layer was plotted in Fig. 4a for both the ascast and blast cleaned specimens. Due to the inhomogeneous microstructure, the hardness values were scattered. Nevertheless, hardness values in the casting skin were in general lower that the averaged bulk hardness plotted at $750 \mu \mathrm{m}$ depth (they were actually measured at and beyond $600 \mu \mathrm{m}$ depth) due to the partial pearlitic microstructure with ferrite grains. Strain hardening from the blast cleaning process was obvious; increased hardness was observed in a surface layer of about $300 \mu \mathrm{m}$ after blast cleaning.

Residual stress profiles from the XRD measurements are presented in Fig. 4b-d together with corresponding diffraction peak width measured in FWHM (Full Width at Half Maximum intensity). Very low thermal stresses from the casting process were found (Fig. 4b). Somewhat lower FWHM in the surface layer was also observed, which could be explained by the presence of polygonal ferrite grains. Such grains are expected to show a smaller diffraction peak width that the thin ferritic lamellar in a pearlite. The blast cleaning induced compressive residual stresses to a large depth, about $800 \mu \mathrm{m}$, as shown in Fig. 4c, and the FWHM profile indicated the penetration of plastic deformation to at least $500 \mu \mathrm{m}$ below surface. At the surface the longitudinal stress was similar to the transverse stress, about $-300 \mathrm{MPa}$, but at the subsurface the peak longitudinal stress, $-420 \mathrm{MPa}$ was in lower magnitude than the peak transverse stress, $-500 \mathrm{MPa}$. The much larger affected depth than normal shot peening was ascribed to the high blasting intensity and the large media size. Actually, a comparable affected depth was reported in [9] for heavy peening of machined specimens of the same material using $0.16 \mathrm{mmC}$ peening intensity and an ever larger depth was reported in [6] for peening of a machined nodular cast iron using $\sim 0.2 \mathrm{mmC}$ peening intensity. The machining employed in this 
study was shown to induce also compressive residual stresses, which, however, only extended to a very shallow depth, about $120 \mu \mathrm{m}$, see Fig. $4 \mathrm{~d}$.
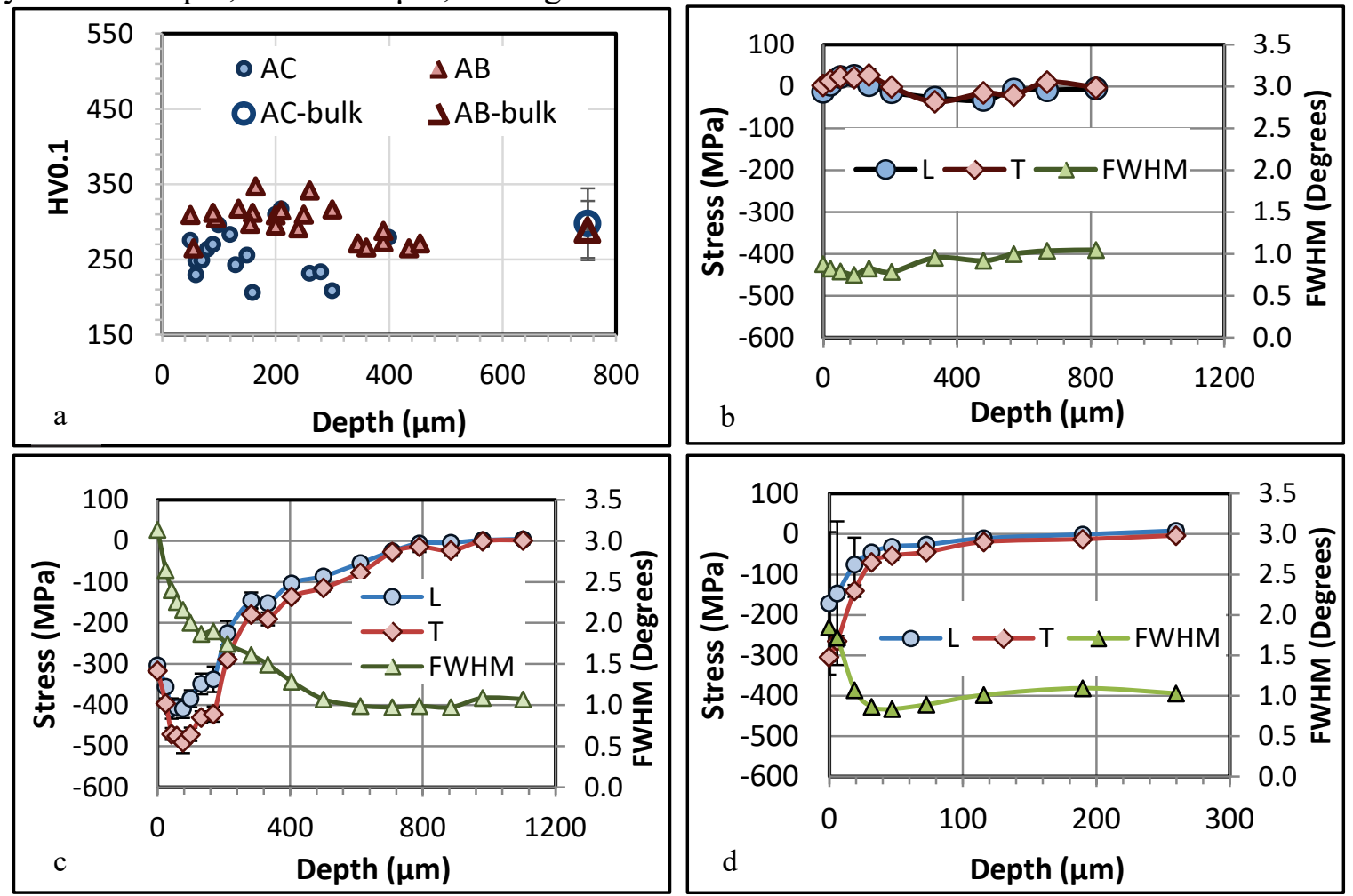

Fig. 4 (a) Hardness profile in as-cast (AC) and as blasted (AB) specimen. (b), (c) and (d) are residual stresses measured along the longitudinal (L) and transverse (T) direction in as-cast (b), as blasted (c), as machined (d) specimens, respectively.

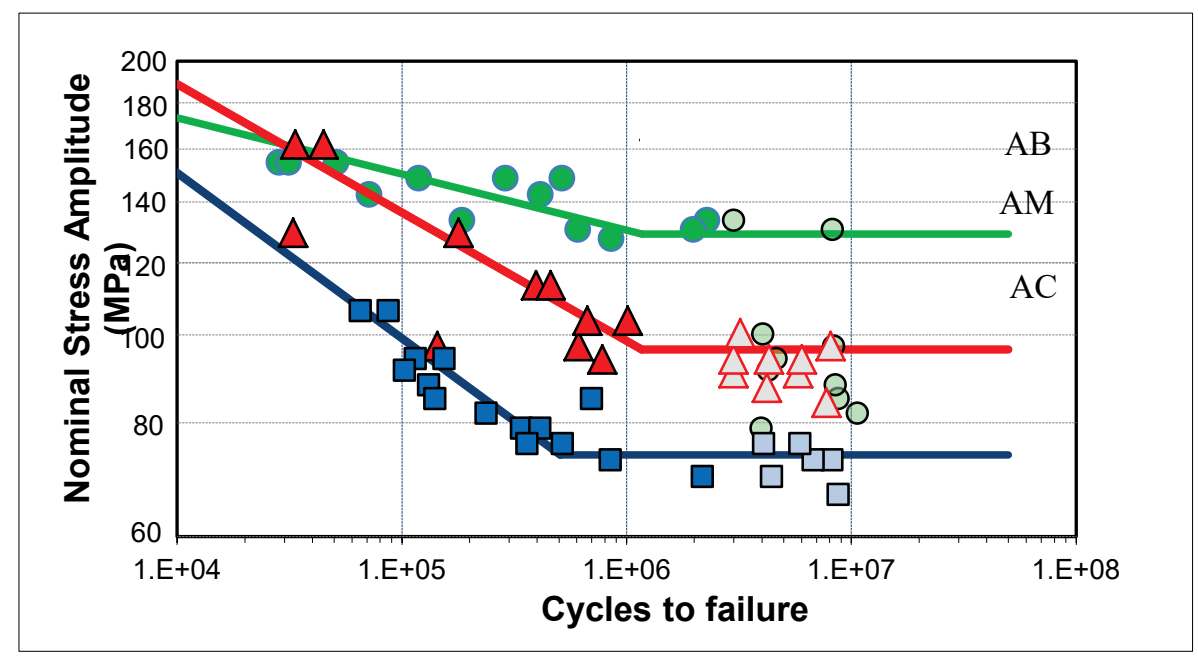

Figure 5. S-N curves for as-cast (AC), as-clean blasted (AB) and as-machined (AM). Filled symbols: failed, open symbols: runout.

Fatigue tests. Results from the bending fatigue tests are presented in Fig. 5 as S-N curves and the derived fatigue limits are given in Table 1. It can be seen that the blast cleaned specimens outperformed the as-cast specimens with better fatigue resistance in both the low cycle fatigue and high cycle fatigue regimes. The fatigue limit was increased by almost $75 \%$, from $73.8 \pm 5.7 \mathrm{MPa}$ for 
the as-cast to $129.1 \pm 3.9 \mathrm{MPa}$ after blast cleaning. The machining also shifted the whole S-N curve upwards, though the improvement was not as significant as the blast cleaning operation: the fatigue limit was $96.4 \pm 6.4 \mathrm{MPa}$, giving a $30 \%$ increase.

Table 1 Fatigue limit with standard deviation derived from the data in Fig. 5 by Dixon method

\begin{tabular}{|l|c|c|c|}
\hline Specimens & As-cast & Blasted & Machined \\
\hline Fatigue limit in MPa & $73.8 \pm 5.7$ & $129.1 \pm 3.9$ & $96.4 \pm 6.4$ \\
\hline Change in \% & - & 74.8 & 30.6 \\
\hline
\end{tabular}

Efforts to locate fatigue initiation points on the fracture surfaces gave no results due to its coarse surface topography. Therefore the analysis below on fatigue crack initiation was based on examination of longitudinal cross-sections of fatigued specimens. For the as-cast specimens, secondary fatigue cracks were observed to form in the surface oxide scale, see e.g. Fig.6 (a) or below the oxide scale, which then propagated inwards along flaky inclusions into the matrix. For the blasted specimens, microcracks (Fig. 6b) were observed to grow from graphite often in the regions $600 \mu \mathrm{m}$ to $900 \mu \mathrm{m}$ below the surface but very few microcracks could be found in the casting skin layer. This indicated that the compressive residual stresses effectively supressed fatigue crack initiation in the casting skin. The fatigue damage and growth process started instead deeper in the specimens where low compressive or even tensile stresses prevailed (Fig. 4c). Outward growth of the cracks towards the surface was also retarded by the compressive residual stresses. As a result, a better fatigue resistance was obtained. Strain hardening could also have contributed to the improvement, the effect was however considered to be minor, as the depth with obvious hardness improvement was much smaller than the depth of compressive stresses (Fig. 4a).

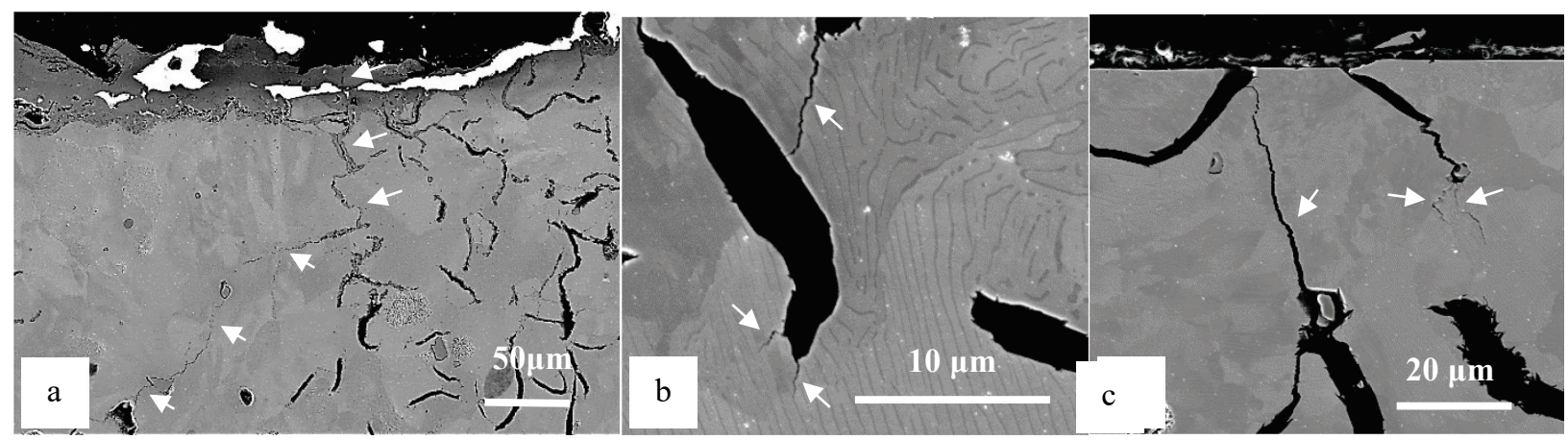

Figure 6 Surface crack iniation and inward propagation in an as-cast specimen (a), subsurface microcracks in a blast cleaned specimen (b), and near surface cracking in a machined specimen (c), indicated by white arrows.

High intensity shot peening applied on machined cast irons were found to be non-beneficial or even to give negative effect on fatigue performance due to increased surface roughness and other damages such as microcracks in subsurface $[8,10]$. Although the blast cleaning process employed here had similar intensity as the shot peening for machined specimens of the same cast iron in [8], due to the ductile casting skin no obvious damage to the surface layer was induced. This could have ensured the benefit of surface enhancement from the blasting.

For the machined specimens, near surface secondary fatigue cracks were observed in association with graphite inclusions, see Fig. 6c. Compressive residual stresses from the machining dropped sharply to very low values within a distance of $40 \mu \mathrm{m}$ from the surface (Fig. $4 \mathrm{~d}$ ) and did not seem to prevent surface/near surface crack initiation from graphite inclusions. However, as the weak casting skin was removed, the surface layer exposed to high applied stresses had better strength, which was 
considered to be the main reason for the observed improvement in fatigue resistance. Machining also improved the surface roughness, however, due to the notch effect of graphite inclusion in grey cast irons, such effect may not be obvious.

\section{Summary}

Four-point bending fatigue tests were performed on a grey cast iron in three different surface conditions: as-cast with casting skin, blast-cleaned and machined (milling). The main results are summarised below:

The blast cleaning process investigated in this study was found to greatly improve the fatigue performance of as-cast specimens in both the low and high fatigue life regimes, with an increase of $75 \%$ in the fatigue limit. The improvement was attributed to that the blasting induced compressive residual stresses to a depth of $800 \mu \mathrm{m}$ and obvious hardening to a depth of more than $300 \mu \mathrm{m}$ but at the same time resulted in little damage in the form of increased surface roughness or microcracking.

The machined specimens showed better fatigue performance than the as-cast specimens, which was mainly due to the removal of the soft casting skin with a brittle outer oxide scale prone to fatigue crack initiation. The fatigue limit was increased by $30 \%$.

The current work shows that in spite of the high peening intensity blast cleaning processes may effectively increase the fatigue properties of as-cast irons with casting skins.

\section{Acknowledgement}

Financial supports from VINNOVA - Sweden's Innovation Agency through the program FFI Strategic Vehicle Research and Innovation are acknowledged.

\section{Reference}

[1] S.S. Mroz, G.M. Goodrich, Quantification of Shot Blast Cleaning Effects on Cast Iron as-cast Surfaces, Transactions of the American Foundry Society, Vol. 114. 114 (2006) 493-506.

[2] S. Boonmee, D. Stefanescu, Effect of casting skin on fatigue properties of CG iron, International Journal of Metalcasting. 7 (2013) 15-26. http://dx.doi.org/10.1007/BF03355550

[3] R. Lin Peng, T. Vuoristo, D. Bäckström, M. Ahmad, M. Lundberg, S. Johansson, Fatigue strength of shot peened compacted graphite iron, ICSP-12, Goslar, Germany (2014).

[4] B. Kaouache, D. Bäckström, M. Ahmad, T. Vuoristo, S. Johansson, R. Lin Peng, To increase fatigue strength of grey iron by shot peening, ICEAF-IV, Skiathos, Greece (2015).

[5] M. Wollmann, S. Koda, L. Wagner, The Influence of Shot Peening on the Fatigue Behavior of Gray Cast Iron and Ductile Iron, in Shot Peening and Other Mechanical Surface Treatments Science and Applications, L. Wagner Ed. Self-publishing (2014).

[6] S. Bagherifard, I. Fernandez-Pariente, R. Ghelichi, M. Guagliano, Effect of severe shot peening on microstructure and fatigue strength of cast iron, Int. J. Fatigue. (2013).

[7] A. Zammit, M. Mhaede, M. Grech, S. Abela, L. Wagner, Influence of shot peening on the fatigue life of $\mathrm{Cu}-\mathrm{Ni}$ austempered ductile iron, Mater. Sci. and Eng. A 545 (2012) 78-85. http://dx.doi.org/10.1016/j.msea.2012.02.092

[8] M. Lundberg, R. Lin Peng, M. Ahmad, D. Bäckström, T. Vuoristo, S. Johansson, Fatigue strength of machined and shot peened grey cast iron, Adv. Mater. Res. 891-892 (2014) 30-35. http://dx.doi.org/10.4028/www.scientific.net/AMR.891-892.30

[9] M. Lundberg, R.L. Peng, M. Ahmad, T. Vuoristo, D. Bäckström, S. Johansson, Residual stresses in shot peened Grey and compact iron, HTM J. Heat Treat. Mater. 69 (2014) 38-45. http://dx.doi.org/10.3139/105.110207

[10] Y. Uematsu, T. Kakiuchi, K. Tokaji, K. Nishigaki, M. Ogasawara, Effects of shot peening on fatigue behavior in high speed steel and cast iron with spheroidal vanadium carbides dispersed within martensitic-matrix microstructure, Mater. Sci. and Eng. A 561 (2013) 386-393. http://dx.doi.org/10.1016/j.msea.2012.10.045 